\title{
A embalagem e rotulagem como elemento de estratégia de marketing
}

\section{Resumo}

A embalagem exerce um papel importante na vida do consumidor: desde a tomada de decisão de compra, a avaliação da marca e nível de uso, além de evitar deteriorização, adulteração ou danificação do produto. Tem aspectos que beneficiam o consumidor como a conveniência e a segurança. Devem desempenhar muitas tarefas tais como: atrair a atenção, descrever características do produto, conquistar a confiança do consumidor e produzir uma impressão global favorável. Uma embalagem bem desenhada contribui para o reconhecimento instantâneo da empresa.

Intrinsecamente ligado à embalagem aparece o rótulo que pode muitas vezes conter apenas a marca do produto como também muitas outras informações. Pode também promover o produto por meio da aparência gráfica atraente.

Para ser bem sucedido em nossos mercados competitivos, o profissional de marketing deve se preocupar com embalagem, marca e garantia.

\begin{abstract}
The packaging accomplishes an important role in the consumer life: since the decision-making process for purchasing, as the trademark evaluation and so the position in a sale ranking., in addition to avoid, deterioration, adulteration or product damage. The packaging has aspects, which benefit the consumer as the convenience and the security. It must to carry out many functions as to attract attention, describe product characteristics, get the consumer' confidence and produce a global and affirmative impression. A well designed packaging contributes for the organization' instantaneous acknowledge

Linked, intrinsically, to the packaging is the label
\end{abstract}

which can just contains the product trademark likewise other information. It can also to promote the product through an attractive graphic appearance.

To be well succeeded in our competitive market, the marketing professional, must to have in mind the packaging, trademark and warranty.

Sendo a embalagem um item de suma importância para a garantia dos clientes, algumas embalagens, como a garrafa de Coca-Cola, são mundialmente reconhecidas e famosas. Atualmente, muitas empresas acrescentam um quinto P (Packaging) aos Ps de Preço, Produto, Promoção e Praça (Distribuição). Assim, a maioria delas trata a embalagem e a rotulagem como elementos de estratégia do produto, caracterizando um recurso que agrega valor.

Este item é tão importante que, segundo Philip Kotler, "a embalagem é o conjunto de atividades design e fabricação de um recipiente ou envoltório para um produto". Outra definição é de Semenik, "em que a embalagem envolve decisões relativas ao recipiente ou rótulo de um produto. A embalagem de uma marca acrescenta uma dimensão estratégica e pode desempenhar um papel importante na diferenciação. Pode, também, afetar o comportamento do consumidor com relação à avaliação da marca e ao nível de uso. A opção por uma embalagem propicia valores para fabricantes, revendedores e consumidores. Uma vez que a mesma representa o tamanho, a forma e a aparência final de um produto no ponto de compra, é parte integrante de todo processo de competir efetivamente no mercado". Uma terceira definição é de McCarthy, para quem "a embalagem envolve a promoção e a proteção do produto. Ela pode ser importante tanto para vendedores como para consumidores. Torna o produto mais conveniente para uso e estocagem. Pode evitar a deterioração, adulteração ou danificação do mesmo.

*Mestrando em Administração de Empresas: Gestão de Negócios, Centro Universitário Sant'Ana. Bacharel em Ciências Econômicas e Administração. Professor das Faculdades Integradas "Campos Salles". 
A boa embalagem facilita a identificação dos produtos e promove a marca no ponto-de-venda e até no uso".

De acordo com Michael Porter, "a capacidade de uma organização competir num dado mercado é constituída pelos seus recursos técnicos e econômicos e, também, por cinco "forças" ambientais, constituindo, cada uma delas, ameaça à entrada da organização em um novo mercado. Deve-se analisar essas forças e propor um programa para influenciá-las ou para se defender delas. Uma estratégia corporativa que verdadeiramente faz crescer a vantagem competitiva de cada unidade de negócio é a melhor defesa contra os ataques de grupos corporativos predatórios". Exemplificando, as cinco forças ambientais são: ameaças à entrada no mercado, o poder de barganha dos consumidores, o poder de barganha dos fornecedores, a ameaça de produto de substituição e a disputa por uma posição em mercados cheios demais.

O que as cinco forças de Porter nos dizem sobre a formulação da estratégia é uma análise dos cinco fatores que podem contribuir para uma avaliação dos pontos fortes e fracos de uma empresa. Mais importante, sobretudo, é que o estrategista deve ser capaz de dar à empresa a melhor posição possível no campo competitivo - inclusive as defesas contra concorrentes atuais e potenciais. Para Porter, esse arcabouço tem implicações para a formulação de estratégia e, quanto maiores forem as forças num determinado ramo e negócio, menores os retornos médios. Portanto, para ser bem-sucedida num ramo que tenha muitos novos concorrentes, numerosos produtos de substituição, alto poder de barganha por parte de consumidores e uma disputa constante por posição entre os competidores, uma empresa deve elaborar cuidadosamente uma estratégia que leve em conta essas forças especificamente.

Uma vez sendo a embalagem um elemento de estratégia do produto, podemos utilizar o modelo de Porter para agregarmos valor de conveniência para o consumidor e promocional para o fabricante. Diversos aspectos da embalagem beneficiam o consumidor, sendo um dos principais benefícios a conveniência. Produtos que têm aplicadores, conta-gotas e que são fáceis de abrir são todos mais convenientes para o consumidor, portanto, mais satisfatórios. E, relacionada à conveniência, está a economia. Embalagens tipo refil e de bico econô- mico são mais econômicas. Também são atraentes as embalagens reutilizáveis.

Um outro valor que uma embalagem pode oferecer é a segurança. Uma tampa "à prova de crianças” ou um frasco inquebrável diminuem o perigo de se manter certos produtos em casa. As embalagens lacradas dão aos consumidores uma sensação de segurança, especialmente nos remédios de venda livre. Enfim, os lenços de papel e os desodorizadores de ambiente, por exemplo: vêm em embalagens decorativas para que fiquem mais atraentes quando usados no lar. A embalagem pode incrementar a aparência estética do produto.

Uma questão importante e de relevância nos tempos modernos, refere-se ao impacto ambiental e ao design das embalagens. Problemas de descarte de resíduos sólidos, poluição gerada durante sua fabricação e desperdício de recursos são questões ligadas à embalagem. Cada vez mais empresas, e mesmo segmentos inteiros, estão enfrentando o desafio da redução dos resíduos e poluição criados por embalagens exageradas e não funcionais. $O$ valor das mesmas para os fabricantes e revendedores dentro do processo de distribuição é consideravelmente auxiliado por uma embalagem bem-desenhada. Distribuidores e varejistas devem desempenhar várias funções que são facilitadas por aquelas fáceis de armazenar, de manusear e de colocar no ponto-de-venda. Embalagens não projetadas para fácil armazenagem e manuseio resultam em despesas maiores para os revendedores. Além disso, aquelas que não protegem o produto adequadamente geram perdas para os membros dos canais de distribuição. Os revendedores preferem marcas que respondam às suas necessidades de manuseio e colocação.

Diante de um mercado consumista com um perfil de consumidor cada vez mais prático, vários fatores têm contribuído para o crescente uso da embalagem como ferramenta de marketing estratégico:

Auto-serviço - a embalagem eficaz opera como um "comercial relâmpago". As embalagens devem desempenhar muitas das tarefas de vendas. Devem atrair a atenção, descrever as características do produto, criar confiança do consumidor e produzir uma impressão global favorável.

Afluência dos consumidores - significa que os 
consumidores estão dispostos a pagar um pouco mais pela conveniência, aparência, confiabilidade e prestígio de embalagens melhores.

Imagem da empresa e da marca - as empresas estão reconhecendo que o poder das embalagens bem desenhadas contribui para o reconhecimento instantâneo da empresa ou marca.

Oportunidades de inovação-a embalagem inovadora pode trazer grandes benefícios aos consumidores e lucro para os fabricantes.

Tendo a embalagem proporcional relevância e destaque, o desenvolvimento de uma embalagem eficaz para um novo produto exige muitas decisões. A primeira tarefa é estabelecer o conceito de embalagem. Esse conceito define o que uma embalagem deve basicamente ser ou fazer para um produto específico. As principais funções da embalagem devem ser: oferecer mais proteção ao produto, introduzir um novo método de abertura, sugerir certas qualidades sobre o produto ou empresas.

Importância estratégica da embalagem - a embalagem envolve a promoção e a proteção do produto. Ela pode ser importante tanto para vendedores como para consumidores. Torna o produto mais conveniente para uso ou estocagem. Pode ainda evitar a deterioração, adulteração ou danificação do mesmo. A boa embalagem facilita a identificação dos produtos e promove a marca no ponto-de-venda e até no uso.

A embalagem pode fazer a diferença - uma nova embalagem pode fazer uma diferença importante em uma nova estratégia de marketing, ao atender melhor às necessidades dos consumidores. Uma eficiente caixa, invólucro, lata ou garrafa pode ajudar a criar um "novo" produto ou um novo mercado.

A embalagem traz uma mensagem - mesmo nos serviços. Ela pode vincular o produto aos demais componentes da estratégia de marketing. Às vezes, uma boa embalagem dá a uma empresa maior efeito promocional do que o obtido através de mídias de propaganda. Os consumidores as vêem nas lojas, por ocasião de suas compras.

A embalagem pode reduzir os custos de distribuição - uma proficiente embalagem protetora é muito importante para fabricantes e atacadistas. Freqüentemente, eles precisam pagar o custo dos bens danificados no transporte e no manuseio, o que pode atrasar a produção ou causar perda de vendas.

Os varejistas também necessitam de boa embalagem - a embalagem protetora pode reduzir os custos de estocagem ao diminuir a quebra, deterioração e roubo. As mais fáceis de se lidar podem reduzir custos ao agilizar a marcação de preço, melhorar o manuseio, exposição e economizar espaço.

O código universal de produtos agiliza a manipulação - para agilizar a manipulação de produtos de venda rápida, representantes do governo e da indústria desenvolveram o código universal de produto, que identifica a embalagem com sinais de barras para leitura através de scaners eletrônicos.

A embalagem socialmente responsável - existe lei que exige que os bens de consumo sejam claramente rotulados e impressos com termos de fácil entendimento, dando, assim, mais informações aos consumidores. Ela também exige que as indústrias procurem reduzir o número de tamanhos de embalagens e tornem os rótulos mais úteis.

Rotulagem - o rótulo representa um subconjunto da embalagem. Os vendedores devem rotular seus produtos. $\mathrm{O}$ rótulo pode ser uma simples etiqueta afixada ao produto ou um desenho artisticamente elaborado que faça parte da embalagem. Ele pode conter apenas a marca do produto ou muitas informações. Mesmo que o fabricante prefira um rótulo simples, a lei exige informações adicionais.

O rótulo desempenha algumas funções. Inicialmente, identifica o produto ou marca; a seguir, classifica-o. Pode, também, descrevê-lo: quem o fabricou, em que local, quando, o que contém, como usá-lo com segurança. Finalmente, pode promover o produto por meio da aparência gráfica atraente.

Decisões éticas - algumas empresas desenham embalagens que ocultam um produto de tamanho reduzido, proporcionando aos consumidores menos pelo dinheiro empregado. Similarmente, alguns varejistas desenham embalagens e rótulos para seus produtos de marca privada que se assemelham e que são facilmente confundidas com marcas de fabricantes. Esforços como esse são antiéticos ou, simplesmente, uma tentativa de tornar a embalagem 
uma parte mais eficaz do composto de marketing? Diferentes pessoas possuem visões diferentes.

A garantia também é importante no planejamento estratégico - uma garantia precisa ser consistente - tem que ser declarada e atraente.
O produto envolve muito mais do que bens físicos e serviços. Para ser bem-sucedido em nossos mercados competitivos, os profissionais de marketing devem preocupar-se com embalagem, marca e garantia.

REFERÊNCIAS BIBLIOGRÁFICAS

KOTLER, Philip. Administração de marketing. São Paulo: Atlas, 1998.

STONER, J.A.F. ; FREEMAN, R.E. Administração. Rio de Janeiro: Prentice - Hall do Brasil, 1985.

MONTGOMERY, C.A. ; PORTER, M. Estratégia - a busca da vantagem competitiva. São Paulo: Campus, 1998.

McCAARTY, J.F; PERREAULT, W.J. Marketing essencial: uma abordagem gerencial e global. São Paulo:Atlas, 1997. 